\title{
Surface structure of thin asymmetric PS-b- $P M M A$ diblock copolymers investigated by atomic force microscopy
}

Article

Accepted Version

Khaydarov, A., Hamley, I. W., Legge, T. and Perrier, S. (2007) Surface structure of thin asymmetric PS-b-PMMA diblock copolymers investigated by atomic force microscopy. European Polymer Journal, 43 (3). pp. 789-796. ISSN 0014-3057 doi: https://doi.org/10.1016/j.eurpolymj.2006.10.006 Available at https://centaur.reading.ac.uk/16615/

It is advisable to refer to the publisher's version if you intend to cite from the work. See Guidance on citing.

To link to this article DOI: http://dx.doi.org/10.1016/j.eurpolymj.2006.10.006

Publisher: Elsevier

All outputs in CentAUR are protected by Intellectual Property Rights law, including copyright law. Copyright and IPR is retained by the creators or other copyright holders. Terms and conditions for use of this material are defined in the End User Agreement.

www.reading.ac.uk/centaur 
Central Archive at the University of Reading

Reading's research outputs online 


\title{
SURFACE STRUCTURE OF THIN ASSYMETRIC PS-b-PMMA DIBLOCK COPOLYMERS INVESTIGATED BY ATOMIC FORCE MICROSCOPY.
}

\author{
A.A. Khaydarov ${ }^{1}$, I.W. Hamley, ${ }^{2 *}$ Thomas M. Legge $^{3}$ Sébastien Perrier, ${ }^{3}$ \\ ${ }^{1}$ Department of Energetic, Ferghana Polytechnic Institute, Ferghana st., 86, 712033 Fergana, \\ Uzbekistan. Telephone: (998-73) 221350; Fax: (998-73) 222781; \\ e-mail: abbas_khaydarov@yahoo.com \\ ${ }^{2}$ Department of Chemistry, University of Leeds, Leeds LS2 9JT, UK. Currently at School of \\ Chemistry, University of Reading, Reading RG6 6AD, UK \\ ${ }^{3}$ Department of Polymer and Colour Chemistry, University of Leeds, Leeds, LS2 9JT, UK
}

\begin{abstract}
Asymmetric poly(styrene- $b$-methyl methacrylate) diblock copolymers of molecular weight $M_{\mathrm{n}}$ $=30,700 \mathrm{~g} / \mathrm{mol}\left(\mathrm{M}_{\mathrm{PS}}=9,600 \mathrm{~g} / \mathrm{mol}, \mathrm{M}_{\mathrm{PMMA}}=20,100 \mathrm{~g} / \mathrm{mol}\right.$ and $\left.P D I=1.15\right)$ and $M_{\mathrm{n}}=63,948$ $\mathrm{g} / \mathrm{mol}\left(M_{\mathrm{PS}}=50,504 \mathrm{~g} / \mathrm{mol}, M_{\mathrm{PMMA}}=13,444 \mathrm{~g} / \mathrm{mol}\right.$ and $\left.P D I=1.27\right)$ were prepared via RAFT polymerization. Atomic Force Microscopy (AFM) was used to investigate the surface structure of thin films, prepared by spin-coating the diblock copolymers on a silicon substrate. We show that the nanostructure of the diblock copolymer depends on the molecular weight and volume fraction of the diblock copolymers. We observed a hexagonal-packed cylindrical patterning for the lower molar mass sample, and a perpendicular lamellar structure for the high molar mass one, Small-angle X-ray scattering investigation of these samples without annealing did not reveal any ordered structure. Annealing of PS-b-PMMA samples at $160{ }^{\circ} \mathrm{C}$ for 24 hours led to a change in surface structure.
\end{abstract}

Keywords: RAFT, Block copolymers; PS-b-PMMA; Thin films; AFM

\section{Introduction}

The ability of block copolymers to form a variety of nanoscale periodic patterns offers the potential to fabricate high-density arrays for use in data storage, electronics, molecular separation and for combinatorial chemistry $[1,2]$. The size of microdomains is determined by the length of the polymer chains and typically is in the range 10-200 $\mathrm{nm}$ which makes block copolymers attractive materials for use as lithographic templates. 
Self-assembly of block copolymers depends on molecular weight, segment size, and the strength of interaction between the blocks, represented by the Flory-Huggins interaction parameter, $\chi$. The morphology depends on $\chi$ and the composition of the copolymer and the volume fraction of one of the constituent blocks [1,3]. For the simplest classes of block copolymers, i.e. diblocks and triblocks, the following structures are known to be stable, as confirmed by theory and experiment: lamellar, hexagonal-packed cylindrical, body-centred cubic, close-packed spherical (which may exhibit only liquid-like ordering) and bicontinuous cubic gyroid structures [1].

In thin films, block copolymers can adopt different morphologies than in bulk. Thin films of symmetric block copolymers form lamellae which can orient either parallel or perpendicular to the substrate. Asymmetric block copolymers which adopt hexagonal or cubic-packed spherical morphologies in the bulk, form parallel cylinders (stripes) or arrays of dots (spheres or perpendicular cylinders) in two dimensions [1]. For diblock copolymer films confined between two infinite, parallel plates, a vertical morphology is possible where the lamellar period of the bulk is realized [4].

The structure of the thin films of symmetric diblock copolymers of $\mathrm{P}(d \mathrm{~S}-b$-MMA $)$ as the interactions between the copolymer and the substrate was investigated by Russell and coworkers using deuterated polystyrene, $d \mathrm{PS}$, to provide contrast for neutron scattering experiments [5]. In cases where there was a strong preferential segregation of one of the components to the substrate, the lamellar microdomains were oriented parallel to the film surface. However, on a nearly neutral substrate, a mixed morphology was found where the lamellae adjacent to the free surface are oriented parallel to the plane of the film, while the lamellae adjacent to the substrate are oriented normal to the plane of the film.

The structure of thin films of a symmetric $\mathrm{P}(d \mathrm{~S}-b-\mathrm{MMA})$ diblock copolymer was investigated near preferential and nonpreferential (neutral) surfaces. For films confined between two continuous neutral surfaces, the orientation of the lamellar microdomains is observed to the perpendicular to the film surfaces throughout the entire film thickness [6]. The structure of lamellar P(S-b-MMA), diblock copolymer films on neutral poly(styrene-ran-methyl methacrylate) brush surfaces was examined as a function of annealing time and film thickness using neutron reflectivity and small-angle neutron scattering. Upon annealing, microphase separation occured quickly with perpendicular and parallel lamellae emanating from the neutral and air surfaces, respectively. This initial growth is followed by a slow increase in the amount of parallel lamellae with a concurrent decrease in the amount of perpendicular lamellae as the samples are annealed further. After long annealing times, the amounts of perpendicular and parallel lamellae do not change significantly. The mixed lamellar structures show a strong 
commensurability trend with film thickness having a period equal to that of the natural lamellar period [7].

In contrast to completely parallel lamellae on silicon wafers having a native oxide layer the perpendicular lamellar orientation was obtained for symmetric PS- $b$-PMMA diblocks on neutral self-assembled monolayers of 3-(p-methoxyphenyl)propyltrichlorsilane covering a silicon substrate [8]. The effect of substrate roughness on the orientation of lamellar microdomains in thin films of symmetric PS- $b$-PMMA diblocks of three different molecular weights was investigated by Sivaniah et al. [9]. It was shown that above a critical substrate roughness all PS- $b$-PMMA polymers adopted a perpendicular lamellar orientation.

In this paper, we have studied thin films of PS- $b$-PMMA diblock copolymers prepared by reversible addition fragmentation chain transfer (RAFT) polymerization. The aim has been to investigate whether polymers compared by this comparatively recently introduced technique adopt morphologies similar to those discussed above, which were observed for polymers prepared by anionic polymerization.

RAFT polymerisation is one of the newest and yet most versatile living radical polymerisation techniques $[10,11]$. The polymerisation process is based on the degenerative chain transfer reaction first reported in the early 1980's [12]. The fast exchange of a thiocarbonyl thio group between propagating and dormant polymeric chains via chain transfer reaction enables a low concentration of radicals to be maintained in solution, thus limiting termination reactions. RAFT therefore allows the synthesis of homopolymers and block copolymers with predictable molecular weight and low polydispersity $(P D I)$.

\section{Experimental section}

Materials. All chemicals were used as received unless otherwise stated. $n$-butyl acrylate (BA) (99\%, Aldrich), $n$-butyl methacrylate (BMA) (99\%, Aldrich) and methyl methacrylate (MMA) (99\%, Aldrich), were purified by passing through aluminium oxide; activated basic Brockmann I (Aldrich). Azobisisobutyronitrile (AIBN) was recrystallized from cold methanol and dried in vacuo overnight. All other chemicals were purchased from Aldrich Chemical Company and used as received unless otherwise stated. All air and moisture sensitive compounds were manipulated using standard Schlenk techniques under a dry nitrogen atmosphere.

Instrumentation. Both ${ }^{1} \mathrm{H}(400 \mathrm{MHz})$ and ${ }^{13} \mathrm{C}(100 \mathrm{MHz})$ Nuclear Magnetic Resonance (NMR) spectra were recorded on a Bruker 400 UltraShield spectrometer at $25^{\circ} \mathrm{C}$ and $d$ chloroform was used as a solvent, unless otherwise stated. 
Molecular weight distributions were recorded using size exclusion chromatography (SEC) at ambient temperature using a system equipped with a Polymer Laboratories $5.0 \mu \mathrm{m}$-bead-size guard column $(50 \times 7.5 \mathrm{~mm})$ and two Polymer Laboratories PLgel $5 \mu \mathrm{m}$ MIXED-C columns (molecular weight range of 2,000,000 - $500 \mathrm{~g} \mathrm{~mol}^{-1}$ ) with a differential refractive index detector (Shodex, RI-101). Tetrahydrofuran was used as an eluent at a flow rate of $1 \mathrm{~mL} \mathrm{~min}{ }^{-1}$ and toluene was used as a flow rate marker. Poly (methyl methacrylate) standards in the range of $1,944,000$ to $1,020 \mathrm{~g} \mathrm{~mol}^{-1}$ were used as calibrants.

Fourier Transform Infra-Red (FTIR) spectra were recorded using a Perkin-Elmer Spectrum One FTIR spectrometer in the region between 4,000 and $400 \mathrm{~cm}^{-1}$, with 100 scans per sample.

\section{Typical Polymerization Procedure}

A solution of methyl methacrylate (MMA), AIBN and chain transfer agent (CTA) in a ratio $500 / 1 / 0.1$ was prepared in toluene ( $50 \mathrm{v} / \mathrm{v} \%$ with monomer). The mixture was deoxygenated by nitrogen gas for 5 minutes, and placed in an oil bath heated at $60^{\circ} \mathrm{C}$. After reaction, the solution was quenched in liquid nitrogen to stop the polymerization. The resulting polymer was recovered by precipitation in hexane. The second block of polystyrene was prepared by using the formed PMMA as macroCTA, using a ratio Styrene (Sty) / PMMA (macro CTA) / AIBN $500 / 1 / 0.1$ ), following the same steps as described above. The various (co)polymers were characterized by ${ }^{1} \mathrm{H}$ NMR and SEC. The number average molecular weight of the block PMMA- $b$-PS were determined to be (i) sample A: $M_{\mathrm{n}}=30700 \mathrm{u}\left(M_{\mathrm{PS}}=9600 \mathrm{u} M_{\mathrm{PMMA}}=20100 \mathrm{u}\right.$, $\left.\mathrm{PD}=1.15, \chi_{\mathrm{PS}}=0.312, \chi_{\mathrm{PMMA}}=0.687\right)$ and (ii) sample $\mathbf{B}: M_{\mathrm{n}}=63948 \mathrm{u}\left(M_{\mathrm{PS}}=50504 \mathrm{u}, M_{\mathrm{PMMA}}=\right.$ $13444 \mathrm{u}, \mathrm{PD}=1.27, \mathrm{PD}=1.18, \chi_{\mathrm{PS}}=0.789, \chi_{\mathrm{PMMA}}=0.210$ ).

\section{Film formation}

Polymer solutions were prepared by dissolving each copolymers in toluene with concentration $1 \mathrm{wt} \%$. Polymer films were prepared by spin coating polymer solutions under ambient conditions onto $\mathrm{SiO}_{\mathrm{x}} / \mathrm{Si}$ substrates, rotated at $\sim 2500 \mathrm{rpm}$ for $1 \mathrm{~min}$. Spin rate and all parameters as described above were kept constant. Film thickness was evaluated by scratching of thin polymer films and was found to be less than $60 \mathrm{~nm}$.

Surface topography of the films was characterised by AFM (Nanoscope III, Digital Instruments) under ambient conditions. AFM images were also obtained for the two PS- $b$ PMMA diblocks following annealing at $T=160{ }^{\circ} \mathrm{C}$ for 24 hours. All imaging was performed in tapping-mode using silicon tips. Topographic and phase images were obtained simultaneously using a resonance frequency of approximately $165 \mathrm{kHz}$ for the probe oscillation. 
SAXS experiments were performed at the Synchrotron Radiation Source (SRS) at Daresbury Laboratory, Warrington, UK. Samples were studied at rest. The static experiments were performed on the beamline 16.1. Camera lengths 1.3, 2.0 and $6.0 \mathrm{~m}$ were used. The wavelength was $\lambda=1.41 \AA$. The wavenumber $q=4 \pi \sin \theta / \lambda$ (scattering angle $2 \theta$ ) was calibrated using a sample of wet collagen.

\section{Results and Discussion}

\section{Block copolymer synthesis}

The use of RAFT polymerization to control the polymerization of MMA and styrene is well documented, and the RAFT process is a well established technique for the synthesis of block copolymers [11]. The process relies on the rapid addition of a propagating radical onto the $\mathrm{C}=\mathrm{S}$ bond of a CTA (1, scheme 1), leading to the formation of an intermediate radical (2, scheme 1). This intermediate can then either reversibly fragment to give back the original radical adduct, or fragment to form a new radical species (See Scheme 1). The design of the CTA is therefore key to the polymerization system. The $\mathrm{Z}$ group (See Scheme 1) should be selected to enhance the reactivity of the $\mathrm{C}=\mathrm{S}$ bond, therefore permitting fast addition of the propagating radicals onto the CTA. The R group (See Scheme 1) should be designed to form a relatively reactive radical, in order to initiate efficiently polymerization by reacting with the monomer, but also it should be stable enough as a radical to fragment from the intermediate radical.

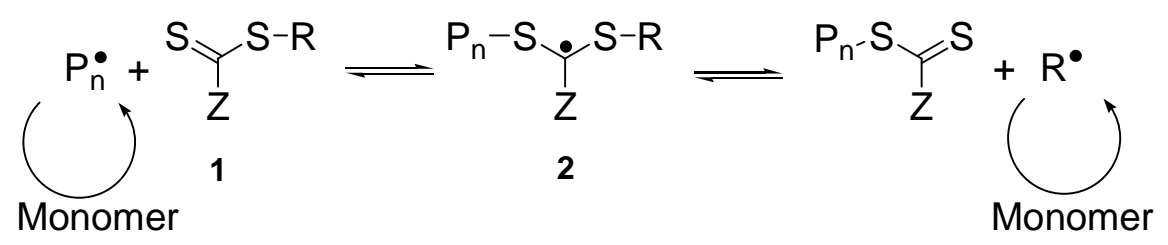

Scheme 1. Proposed mechanism of RAFT polymerization.

This last feature is key to the synthesis of block copolymers. Block extending experiments in RAFT mediated polymerization occur when the first block from the macroCTA fragments in preference to all other possible leaving groups. For this to happen, the chain formed from the second batch of monomers $\left(\mathrm{P}_{\mathrm{n}}\right.$ in scheme 1$)$ must form a propagating radical that is less stable than that of the chain formed from the first monomer ( $R$ in scheme 1). Indeed, the fragmentation of $P_{n}$ from the intermediate radical 2 is therefore less favoured than that of $R$. This pushes the equilibrium towards fragmentation of the first block, introducing homopolymers with radically active chain ends into the system. Therefore, in the case of PMMA / PS block copolymerization, the PMMA block should be polymerized first, as it is a 
better fragmenting group than the PS block, based on its polarity and steric hindrance (See Scheme 2).[13]

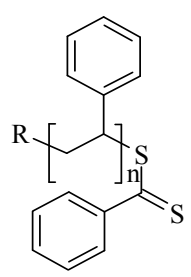

PS macroCTA

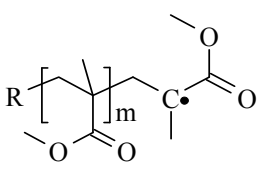

PMMA radical

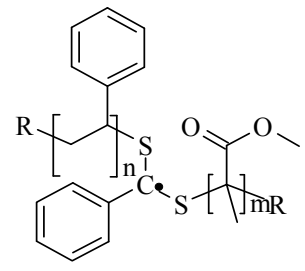

Stabilised radical intermediate

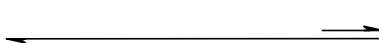

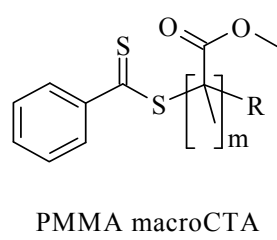

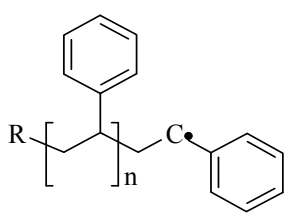

PS radical

Scheme 2 Relevance of monomer reactivity on block copolymer synthesis by RAFT

\section{Morphology Study}

Figure 1 a,c shows AFM the topographic (height) and phase images of PS-b-PMMA samples with average molecular masses of sample B. The phase image indicates ordered structures of the diblock copolymer film. In the phase image bright and dark domains are evident. Apparent in the images, the bright domains take up more area of the total area. Based on the morphology expected for diblocks of this composition, it seems that blocks of the minority PMMA form hexagonal-packed cylinders oriented normal to the plane of film in the PS matrix. Figure $1 \mathrm{~b}$ shows the topography and phase images of the same PS- $b$-PMMA copolymer sample annealed at $160{ }^{\circ} \mathrm{C}$ for 24 hours. The topography images of copolymer samples still were smooth and without any features on the surface. However, we observed an increase in the size of PS domains in phase images (Figure 1d). Blocks in diblock copolymers with the lower surface free energy will preferentially segregate to the surface [14]. Indeed, in our samples PS have lower surface free energy $\left(\gamma=40.2\right.$ and $41.2 \mathrm{mJm}^{-2}$ for PS and PMMA [15], respectively). Consequently, PS blocks in will segregate in the surface and size of PS domains will increase.

Figure 2 a,b shows height and phase images for sample A. The phase image provides evidence for a perpendicular lamellar structure since a "stripey" pattern is evident. This could also arise from cylinders aligned parallel to the substrate, however this is unlikely as there is no suggestion of perpendicular cylinder domains as would be expected for an unannealed sample. A symmetric PS- $b$-PMMA diblock with $M_{\mathrm{n}}=93000$, a polydispersity of 1.09 obtained on the 
surface forms also alternating lamellae upon phase separation when surface of silicon substrate was anchored with $\mathrm{s}$ hydroxyl terminated random copolymer of styrene and methylmetacrylate[12]. Figure 2c,d shows the topography and phase images the same copolymer film obtained for annealed at temperature and for 24 hours. After annealing process a surface of samples very restrictly changing. In the both AFM images (the topography and phase image) we have observed inverted lamellar structure to body-center-cubic (bcc) spheres. Propably, in process annealing PMMA blocks inverted to spheres in a PS matrix.
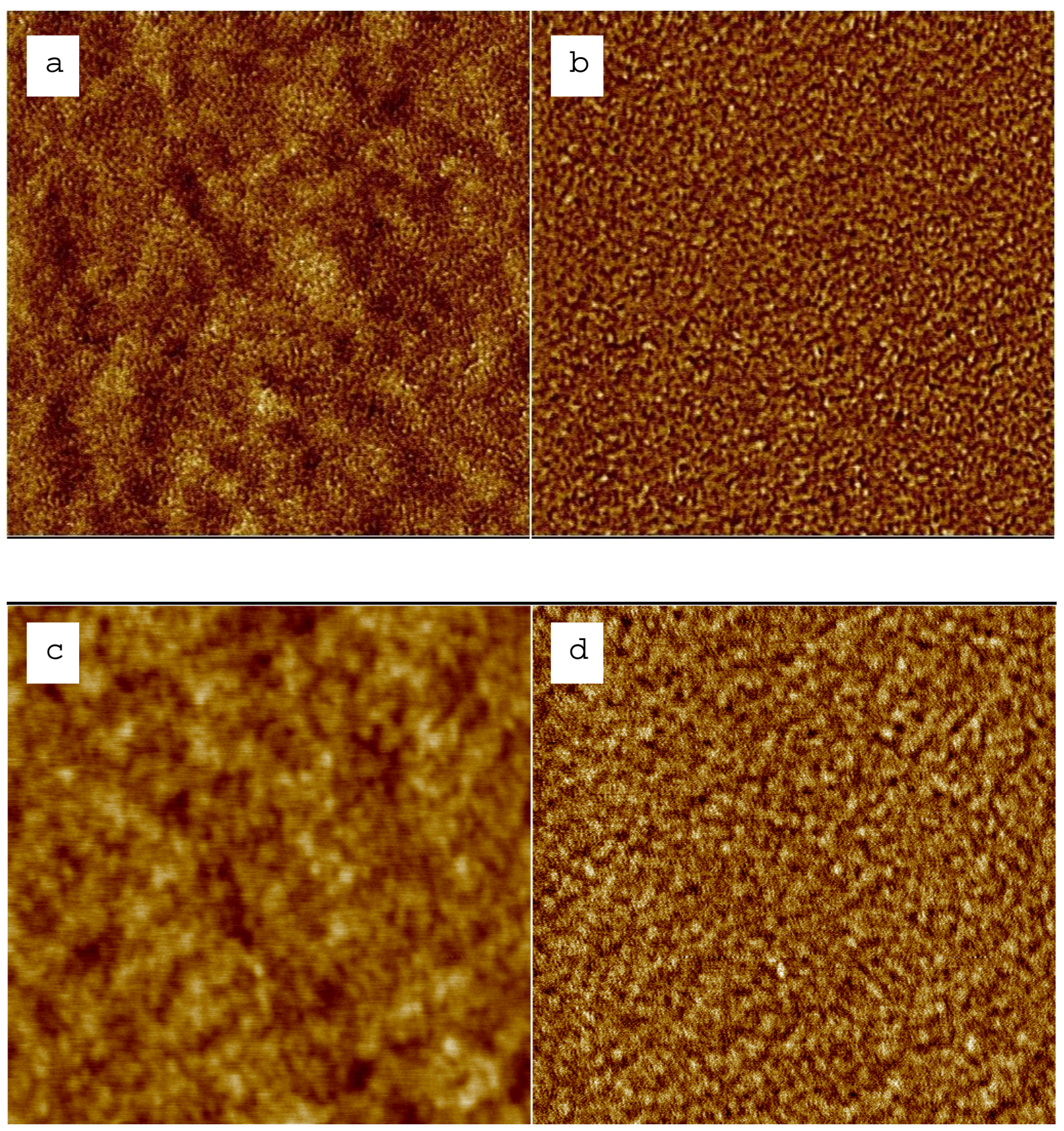

Figure 1. Height and phase images of thin films of sample $\mathbf{B}$ obtained by spin coating before (a,b) and after (c,d) annealing at $160{ }^{\circ} \mathrm{C}$ for 24 hours. Image size $1 \mathrm{x} 1 \mu \mathrm{m}$. Height scale is a) $3 \mathrm{~nm} \mathrm{c)} 4 \mathrm{~nm}$. Phase scale (Deg) is $\quad$ b) $12.00^{\circ}$ d) $5.00^{\circ}$. 

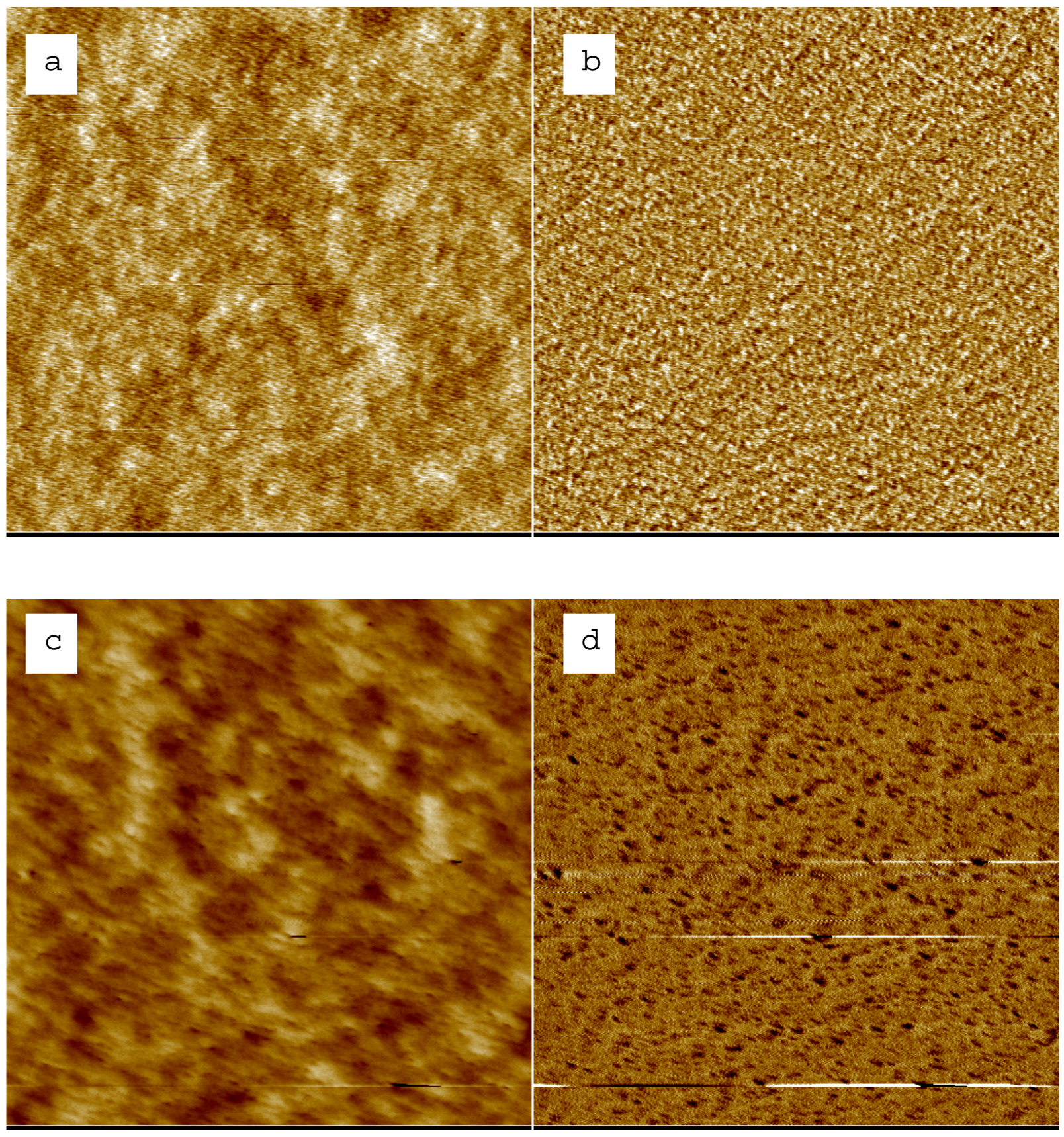

Figure 2. Height and phase image of thin films of sample A obtained by spin coating before (a,b) and after (c,d) annealing at $160{ }^{\circ} \mathrm{C}$ for 24 hours.. Image size $1 \times 1 \mu \mathrm{m}$ for a,b and $2 \times 2 \mu \mathrm{m}$ for c,d. Height scale is a) $5.55 \mathrm{~nm}$ c) $5 \mathrm{~nm}$. Phase scale (Deg) is $\quad$ b) $3.08^{\circ}$ d) $6.00^{\circ}$. 


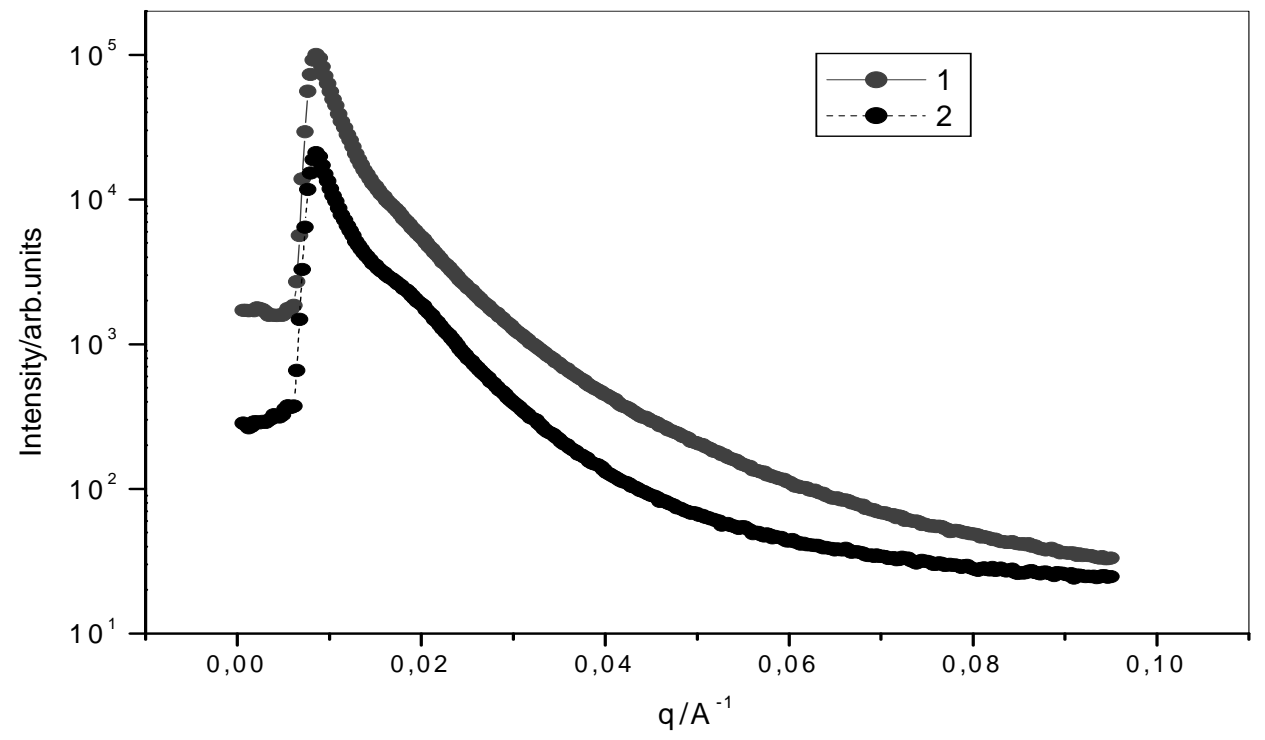

Figure 3. SAXS data obtained for PS- $b$-PMMA samples at $22{ }^{\circ} \mathrm{C}$. (1) Sample B; (2) Sample A

Small-angle X-ray scattering is an excellent technique to probe the morphology of ordered phases in block copolymer melts, solids, and gels. The relative positions of a sufficient number of reflections arising from microstructure periodicities enable unambiguous identification of morphology [3]. For lamellar and hexagonal-packed cylinder morphology the ratios of the peak positions $1: 2: 3: 4$ and $1: \sqrt{3}: \sqrt{7}: \sqrt{9}$, respectively. We have measured SAXS profiles for both PS- $b$-PMMA samples and Figure 3 presents SAXS data obtained at room temperature. Small-angle scaterring data for both PS-b-PMMA samples exhibit a single broad reflection near $q=0.02 \AA^{-1}$, corresponding to a microphase separated structure with $d=300 \AA$. The lack of higher order reflections prohibits identification of morphology (which however was determined from APM in thin films) and indeed suggests a lack of long-range order. This may be due to the relatively high polydispersity of the samples, at least compared to chemically similar diblocks prepared by anionic polymerization. 


\section{Conclusions}

AFM was used to investigate the surface structure of thin films of asymmetric polystyrene- $b$ poly(methyl methacrylate)(PS- $b$-PMMA) diblock copolymer of two different molar masses. Thin films were prepared by spin coating on silicon. AFM images indicated distinct structures dependent on composition. It was observed that at low molar masses of PS-bPMMA will form the hexagonal-packed cylindrical patterning and at high molecular masses will be forming perpendicular lamellar structure. [???] Annealing of PS-b-PMMA samples at temperature $160{ }^{\circ} \mathrm{C}$ and duration 24 hours to lead to changing surface structure. Small-angle $\mathrm{X}$-ray scattering investigation of these samples indicated microphase separation without longrange order. The lack of long range order may be due to the polydispersity of the samples. Confinement in a thin film leads to enhanced ordering due to surface effects, and this can be imaged by AFM.

\section{Acknowledgments.}

A.A.Kh. would like thank to the Royal Society for funding an International Incoming Short Visit to the University of Leeds. We are grateful to Anthony Gleeson and Valeria Castelletto for assistance with the SAXS experiments. 


\section{References}

[1] Hamley IW. Nanotechnology 2003;14:R39-54.

[2] Collins S, Hamley IW, Mykhaylyk T. European Polymer Journal 2004;40:1715-1721.

[3]. Hamley IW. The Physics of Block Copolymers; Oxford University press: Oxford, 1998.

[4]. Walton DG, Kellogg GJ, Mayes AM, Lambooy P, Russell TP. Macromolecules 1994;

27: $6225-6228$.

[5]. Mansky P, Russell TP, Hawker CJ, Pitsikalis M, Mays J. Macromolecules 1997; 30: 6810-6813.

[6] Huang E, Mansky P, Russell TP; Harrison C, Chaikin PM, Register RA, Hawker CJ, Mays J. Macromolecules 1998; 31: 7641-7650.

[7] Huang E, Mansky P, Russell TP; Harrison C, Chaikin PM, Register RA, Hawker CJ, Mays J. Macromolecules 2000; 33: 80-88.

[8]. Sohn BH, Yun SH. J. Polymer 2002;43: 2507-2512.

[9]. Sivaniah E, Hyashi Y, Matsubara S, Kiyono S, Hashimoto T, and et. al. J. Macromolecules 2005; 38: 1837-1849.

[10]. Chiefari, J.; Chong, Y. K.; Ercole, F.; Krstina, J.; Jeffery, J.; Le, T. P. T.; Mayadunne, R. T. A.; Meijs, G. F.; Moad, C. L.; Moad, G.; Rizzardo, E.; Thang, S. H. Macromolecules 1998, $31,5559$.

[11]. Perrier, S., Takolpuckdee, P. J. Polym. Sci. Pol. Chem. 2005, 43, 5347.

[12]. Delduc, P., Tailhan, C., Zard, S. Z. J. Chem. Soc.-Chem. Commun. 1988, 308.

[13]. Moad, G.; Mayadunne, R. T. A.; Rizzardo, E.; Skidmore, M.; Thang, S. H. Macromolecular Symposia 2003, 192, 1-12.

[11]. Zhang Q, Tsui O.K.C, Du B, Zhang F, tang, He T. J. Macromolecules 2000; 33: 95619567.

[12]. Zhang Q, Xu T, Butterfield D, Misner MJ, Ryu DY, Emrick T, Russell T.P. J. Nano letters 2005 ; 36: 357-361.

[13]. Golbach JT, Russel TP, Penelle. J. Macromolecules 2002; 35: 4271-4276.

[14]. Kailas L, Nysten B, Bertrand. J. Surface and interface analysis 2004; 36: 1227-1230.

[15] Ton-That C, Shard AG, Teare DOH, Bradley RH. Polymer 2001;42: J. Macromolecules 2000; 33: 1121-1129. 
